\title{
Tumor syndrome, hepatic and hematological features revealing undiagnosed early rheumatoid arthritis
}

\author{
Zeineb Alaya*, Mouna Braham and Elyès Bouajina \\ Department of Rheumatology, Farhat Hached Hospital, Faculty of Medicine of Sousse, Sousse, Tunisia
}

\begin{abstract}
Background: Exta-articular manifestations in rheumatoid arthritis (RA) are rare and generally occur in an advanced stage of the disease. We report a case of an unusual onset of early RA.

Case presentation: A 21-year-old male complains of polyathritis involving small and large joints, associated with fever, asthenia, anorexia and weight loss. The temperature was up to $38.8^{\circ}$. There was a left cervical adenopathies, an hepato-splenomegaly, and there were synovitis in all joints sparing distal interphalangial joints. The erythrocyte sedimentation rate was accelerated, the C-reactive protein was up to $222 \mathrm{mg} / \mathrm{l}$. The number of white blood cells were $9000 / \mathrm{mm} 3 \mathrm{with}$ monocytosis, lymphocytosis and thrombocytosis at $986000 / \mathrm{mm}^{3}$. There was cholestasis with cytolysis. Rheumatoid factor (RF) and anti-cyclic citrullinated peptide antibodies (ACCP) were positive. The hands X-Ray didn't show any RA specific signs. The chest X-Ray showed a left pleurisy. The CT scan showed multiple axillar and mediastinal lymphadenopathies, hepato-splenomegaly with multiple coelio-mesenteric and retroperitoneal lymph nodes. The pleural biopsy as well as the biopsy of the adenopathy and the salivary glands didn't show any specific abnormalities or signs of lymphoma. The hepatic biopsy revealed an inflammatory lymphohistiocytic infiltrate with rare foci of necrosis and a dilatation of the hepatic sinusoids. The diagnosis of RA was suspected and confirmed by the MRI of the hands.
\end{abstract}

Conclusion: RA may have an unusual onset such as hematologic, hepatic, pleuropulmonary features or tumor syndrome, but it is rarely reported. The diagnosis in this case is difficult.

\section{Introduction}

Rheumatoid arthritis (RA) is a chronic autoimmune inflammatory disease, characterized by a severe joint involvement [1]. It can involve other organs and tissues as well as synovial joints [2]. Extra-articular manifestations are all systemic features which are indirectly related to the locomotor system [3], and there is no clear classification for these manifestations [2]. In RA, extra-articular manifestations are present in about $40 \%$ of cases in the course of their disease [4], and generally occur in an advanced stage of the disease [1]. But in rare cases, they can be present in early RA [5,6]. These events can affect both sexes, and can occur at any age [2]. Patients with high levels of rheumatoid factor $(\mathrm{RF})$, are more exposed to develop extra-articular manifestationsin the course of RA such as rheumatoid nodules, rheumatoid vasculitis, and pleuropulmonary, cardiovascular, neurologic, digestive, cutaneous, hematologic, and ocular complications [7-9]. The most frequently observed are rheumatoid nodules, osteoporosis, Gougerot's syndrome, pleuropulmonary, hepatic and renal manifestations. We reported acaseof an early diagnosed RA patient with very rare extra-articular manifestations: axillar, mediastinal and intra-abdominal lymphadenopathies and hepatosplenomegaly, with hematological features.

\section{Case presentation}

A 21-year-old male who was referred to our department for exploration of polyathritis since one month, involving small and large joints (all joints except the distal inter-phalangial joints of hands), in a context of high fever, asthenia, anorexia and weight loss. On physical examination, the temperature was up to $38.8^{\circ}$, there was a left cervical adenopathies, an hepato-splenomegaly, and there were synovitis in all joints sparing distal inter-phalangial joints. The erythrocyte sedimentation rate was accelerated, the $\mathrm{C}$-reactive protein was up to $222 \mathrm{mg} / \mathrm{l}$. The number of white blood cells were $9000 / \mathrm{mm} 3$ with monocytosis, lymphocytosis and thrombocytosis at $986000 / \mathrm{mm} 3$. The hepatic biology showed a cholestasis (eight times the normal value) and a cytolysis (three times the normal value) (Table 1) with negative antibodies anti smooth muscle, anti LKM1 and anti-mitochondrial antibodies. Rheumatoid factor (RF) found by the Latex and RoseWaller reaction (IgG, IgA, IgM) and anti-cyclic citrullinated peptide antibodies (ACCP) measured by ELISA were positive (160, 110, 330 and $719 \mathrm{UI} / \mathrm{L}$ respectively). Anti-nuclear antibodies are negative. Infectious endocarditis was eliminated by normal cardiac ultra-sound and negative blood cultures. Wright serology and the card test were negative. Viral serology (hepatitis B and C) was negative, anti EBV was positive to IgM and IgG, anti CMV was positive to IgG, and parvovirus serology was negative. Tuberculosis explorations were all negative. The hands X-Ray didn't show any RA specific signs. The chest X-Ray showed a left pleurisy (Figure 1). The CT scan showed multiple axillar and mediastinal lymphadenopathies, hepato-splenomegaly (Figure 2) with multiple coelio-mesenteric and retroperitoneal lymph nodes (Figure 3). The pleural biopsy as well as the biopsy of the adenopathy and the salivary glands didn't show any specific abnormalities or signs of lymphoma. The hepatic biopsy revealed an inflammatory

Correspondence to: Zeineb Alaya, Department of Rheumatology, Farhat Hached Hospital, Faculty of medicine of Sousse, Ibn el Jazzar Street, 4000 Sousse, Tunisia. Tel: +21698375975; E-mail: zeineb_a@hotmail.fr

Key words: rheumatoid arthritis, fever, lymphadenopathy, hepatomegaly, hepatic biopsy, pleurisy

Received: November 2, 2017; Accepted: December 29, 2017; Published: January 03, 2018 


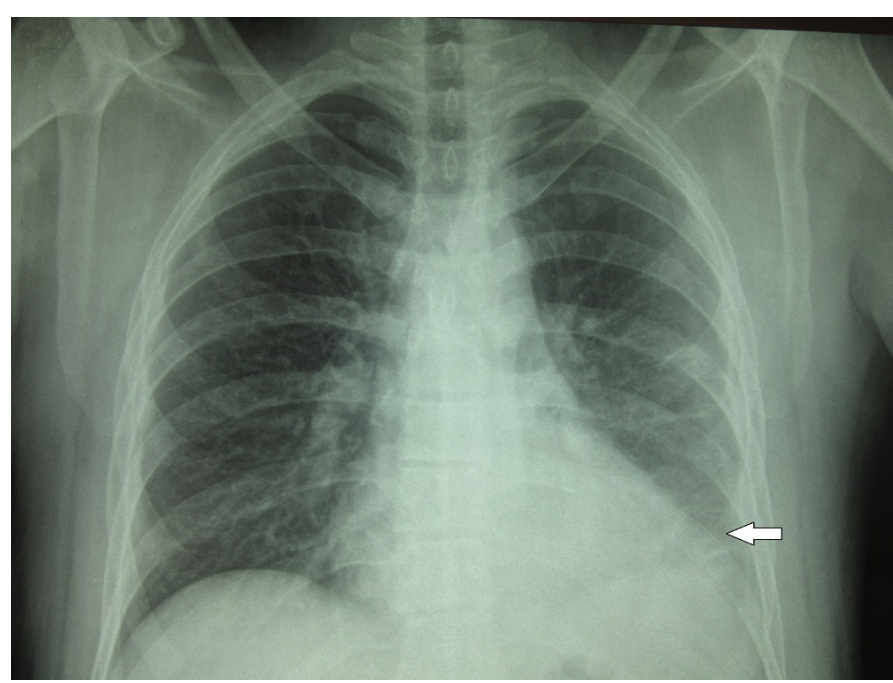

Figure 1. The chest X-Ray showed a left pleurisy.

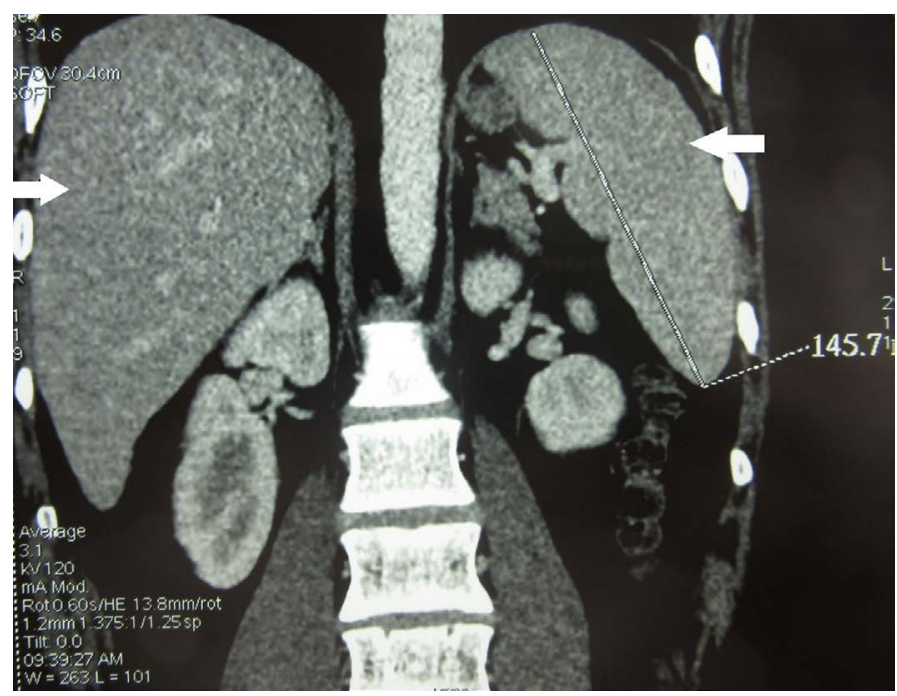

Figure 2. The CT scan showed hepato-splenomegaly.

lymphohistiocytic infiltrate with rare foci of necrosis and a dilatation of the hepatic sinusoids. After eliminating malignant haemopathy essentially lymphoma, connective tissue disease, chronic tuberculosis and viral infection, the diagnosis of RA was suspected. The MRI of the hands was practiced and showed evident synovitis of the fingers with bone edema of the phalanges (Figure 4). The patient was diagnosed with RA basing on ACR 1987/EULAR 2010, Rheumatoid Arthritis Classification Criteria [10,11], and was treated with corticosteroids at a dose of $1 \mathrm{mg} / \mathrm{Kg}$. The evolution was marked by the absence of fever in two days, the regression of the inflammatory biological syndrome, the disappearance of cytolysis, the reduction of cholestasis and the improvement of synovitis. After six months, we obtained a normalization of the hematologic and liver balance (Table 1), the regression of the tumor syndrome and the disappearance of the pleurisy in the CT-scan. The hands X-Ray showed bilateral radio-carpian and inter-carpian narrowing and two geodes in the fifth right metacapophalangian (Figure 5). The patient was treated with methotrexate at a dose of $15 \mathrm{mg} /$ week, but, he still complaining with many synovitis and high disease activity. So, a biological treatment with anti-TNF alpha is recommended.

\section{Discussion}

Extra-articular manifestations in RA generally occur in advanced stage of the disease, contrarily of our patient whose many unusual features were present at the moment of RA diagnosis. He presented exceptional signs like the cervical, axillar and mediastinal lymphadenopathies, which suggested a lymphoma or other tumor. In fact, the Bilateral mediastinal and hiliaire adenopathies have also been reported in RA $[12,13]$. However, if there are peripheral adenopathies, palpable ones are found in $30 \%$ of RA cases $[12,13]$. Intrathoracic lymphadenopathies, in particular mediastinal, have been very rarely described in the literature $[12,13]$. In the study of Remy-Jardin et al. [14], the thoracic CT revealed intrathoracic adenopathies in nine of 84 patients with RA. In a series of 46 patients, Despaux [15] found

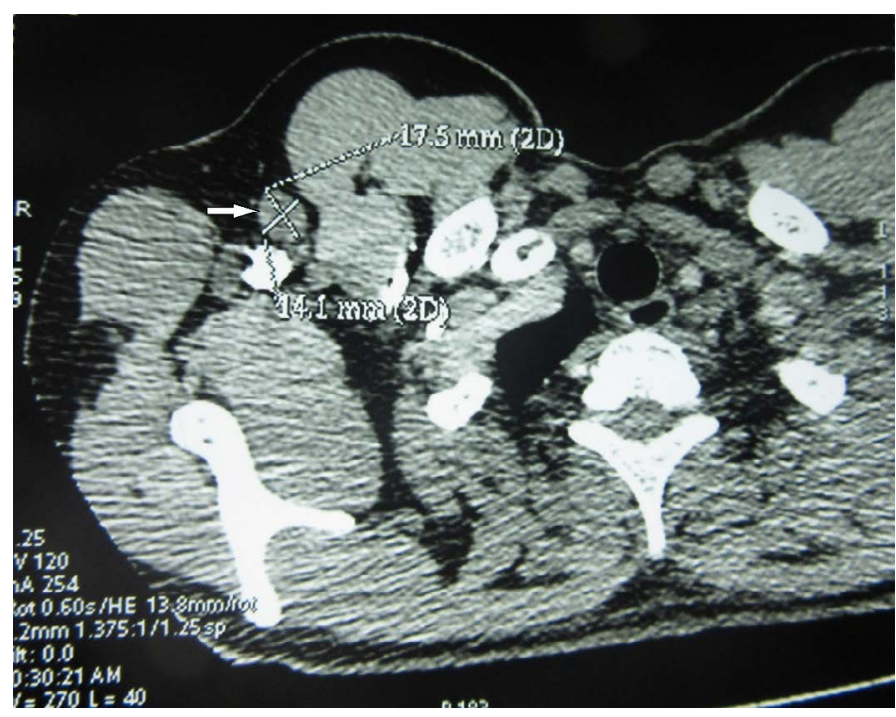

Figure 3. The CT scan showed multiple coelio-mesenteric and retroperitoneal gonglia.

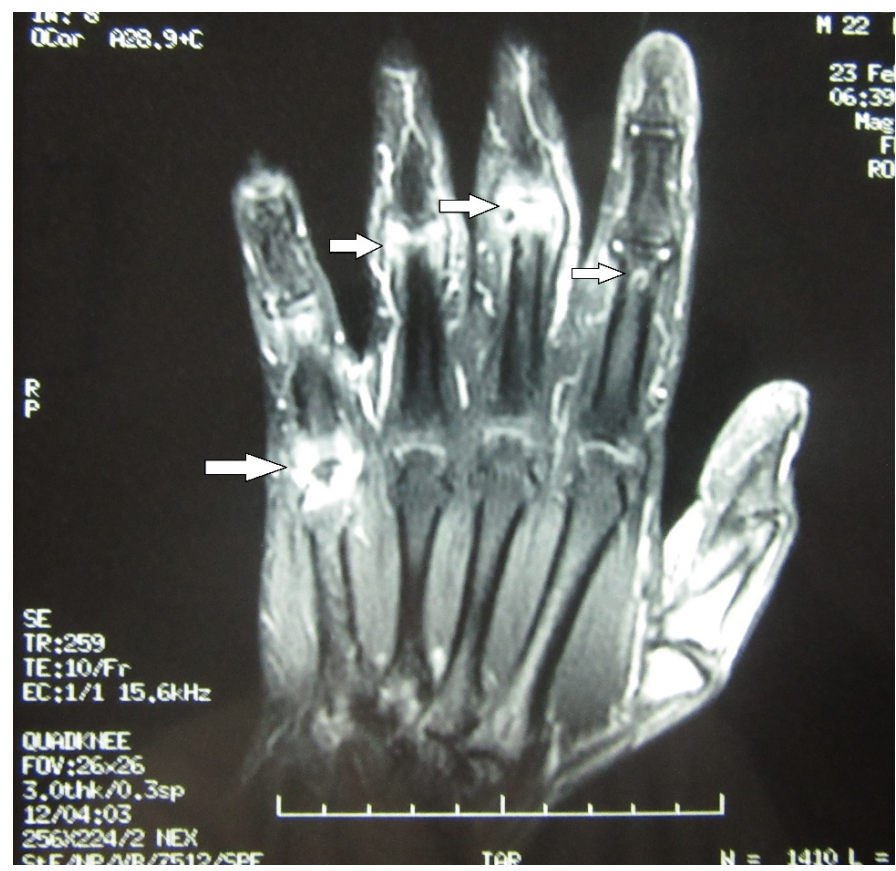

Figure 4. MRI of the hands showed synovitis at the 5 th finger metacarpophalangeal and proximal interphalangeal sites at the 2.3 and 4 th fingers. There was also a bone edema of all the proximal interphaplangiennes and the metacarpophalangeal of the 5 th finger. The tendons are of signal and morphology preserved. 
Table 1. Showed the evolution of biological findings.

\begin{tabular}{|c|c|c|c|}
\hline & First biological results & 3 months after & 6 months after \\
\hline White cells (elements/ml) & 9000 & 17700 & 11300 \\
\hline Lymphocytes (elements/ml) & 1600 & 5000 & 4600 \\
\hline Monocytes (elements/ml) & 1100 & 1300 & 900 \\
\hline Platelets (elements/ml) & 986000 & 293000 & 370000 \\
\hline C-Reactive protein $(\mathrm{mg} / \mathrm{L})$ & 222.2 & 7.8 & 5.5 \\
\hline $\operatorname{ASAT}(\mathrm{U} / \mathrm{L})$ & 21 & 13.4 & 22 \\
\hline $\operatorname{ALAT}(\mathrm{U} / \mathrm{L})$ & 139 & 32.2 & 18 \\
\hline Gamma glutamyl transaminase (GGT) (U/L) & 382.2 & 30.9 & 33 \\
\hline Alcalin Phosphatase (U/L) & 92.5 & 27.6 & 24 \\
\hline
\end{tabular}

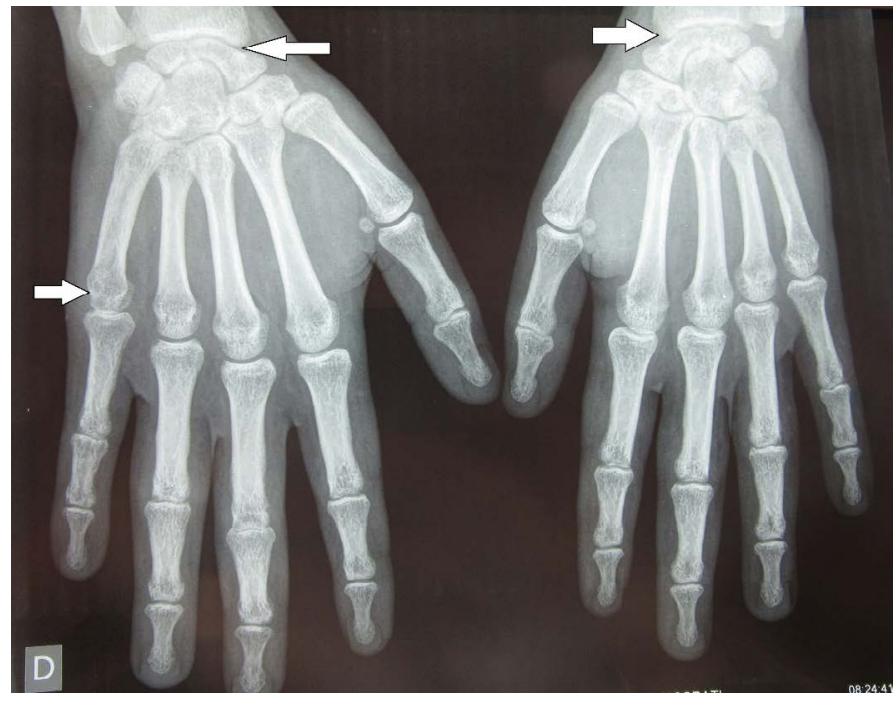

Figure 5. The hands X-Ray showed bilateral radio-carpian and inter-carpian pinching and two geodes in the fifth right metacapo-phalangian.

intrathoracic lymphadenopathy revealed by CT in 13 patients. Marilier S. et al. [12], reported the observation in of an elderly woman aged of 83 years with a rheumatoid pleurisy, pericardial effusion and mediastinal and axillary adenopathies. All these signs have been linked to rheumatoid arthritis, which was reinforced by the good evolution under specific treatment of RA. However, the discovery of mediastinal adenopathies in a patient with RA causes fear above all malignant cause justifying an exhaustive etiological investigation [16].

Concerning gastrointestinal complications in RA, in most cases, they are caused by mediations [17]. Exceptionally, the affection of the gastrointestinal system can be caused by mesenteric vasculitis [17]. Our patient presented an hepato-splenomegaly with multiple coelio-mesenteric and retroperitoneal ganglia, which wasn't reported in the literature. Hepatic manifestations in RA can be observed with hepatomegaly which is seen in $22 \%$ of patients by scintigraphic scanning and correlates with the elevation of RF $[18,19]$. Massive hepatomegaly can occur in juvenile RA, and is associated with fever and mild perturbation of liver function [19]. Transaminases and bilirubin are usually normal in RA [19]. But serum alkaline phosphatase (AP) is increased in $18-46 \%$ of cases and is correlated with the activity of RA in some studies [19]. Gamma glutamyl transaminase (GGT) is elevated in $23-77 \%$ of patients and correlates with active disease [19]. The liver histologic abnormalities were found in $92 \%$ of patients with RA in an autopsy study [20], and 65\% in a clinical study [21]. They are usually mild and can be correlated with the disease activity [21]. The most frequent are congestion, periportal fibrosis, portal tract inflammation, fatty liver [21], sinusoidal dilatation [22], amyloid, and, rarely, cirrhosis [20].
Hematological manifestations in RA such as anemia, neutropenia, thrombocytopenia, thrombocytosis and eosinophilia, can occur either at the moment of diagnosis or during the disease course [23]. Thrombocytosis is frequent in active RA and is correlated with the number of active inflamed joints [24].

Extra-articular manifestations in RA are serious and they should be aggressively treated and monitored [2]. There aren't specific treatments and generally they stabilize with optimized treatment of the RA.

\section{Conclusion}

Extra-articular manifestations in RA are dominated by cardiac, pulmonary, hepatic, ocular ones and Sjogren syndrome. Unusual features like tumor syndrome and hematological perturbations should be seriously considerate. In all cases, an exhaustive investigation is necessary to eliminate infectious or malignant causes.

\section{Competing interests}

The authors declare no competing interest.

\section{References}

1. Lee JE, Kim IJ, Cho MS, Lee J (2017) A Case of Rheumatoid Vasculitis Involving Hepatic Artery in Early Rheumatoid Arthritis. J Korean Med Sci 32: 1207-1210. [Crossref]

2. Cojocaru M, Cojocaru IM, Silosi I, Vrabie CD, Tanasescu R (2010) Extra-articular Manifestations in Rheumatoid Arthritis. Maedica (Buchar) 5: 286-291. [Crossref]

3. Mielants H, Van den Bosch F (2009) Extra-articular manifestations. Clin Exp Rheumatol 27: S56-61. [Crossref]

4. Cimmino MA, Salvarani C, Macchioni P, Montecucco C, Fossaluzza V, et al. (2000) Extra-articular manifestations in 587 Italian patients with rheumatoid arthritis. Rheumatol Int 19: 213-217. [Crossref]

5. Turesson C, Jacobsson L, Bergstrom U (1999) Extra-articular rheumatoid arthritis: prevalence and mortality. Rheumatology (Oxford) 38: 668-674. [Crossref]

6. Young A, Dixey J, Cox N, Davies P, Devlin J, et al. (2000) How does functional disability in early rheumatoid arthritis (RA) affect patients and their lives? Results of 5 years of follow-up in 732 patients from the Early RA Study (ERAS). Rheumatology (Oxford) 39: 603-611. [Crossref]

7. Gabriel SE, Crowson CS, Kremers HM, Doran MF, Turesson C, et al. (2003) Survival in rheumatoid arthritis: a population-based analysis of trends over 40 years. Arthritis Rheum 48: 54-58. [Crossref]

8. Turesson C, O'Fallon WM, Crowson CS, Gabriel SE, Matteson EL (2003) Extraarticular disease manifestations in rheumatoid arthritis: incidence trends and risk factors over 46 years. Ann Rheum Dis 62: 722-727. [Crossref]

9. Hochberg MC, Johnston SS, John AK (2008) The incidence and prevalence of extra-articular and systemic manifestations in a cohort of newly-diagnosed patients with rheumatoid arthritis between 1999 and 2006. Curr Med Res Opin 24: 469-480. [Crossref]

10. Arnett FC, Edworthy SM, Bloch DA, McShane DJ, Fries JF, et al. (1988) The American Rheumatism Association 1987 revised criteria for the classification of rheumatoid arthritis. Arthritis Rheum 31: 315-324. [Crossref] 
11. Radner H, Neogi T, Smolen JS, Aletaha D (2014) Performance of the 2010 ACR/ EULAR classification criteria for rheumatoid arthritis: a systematic literature review. Ann Rheum Dis 73: 114-123. [Crossref]

12. Marilier S, Martin-Pfitzenmeyer I, Mazen E, Da Silva S, Pfitzenmeyer P, et al. (2009) Décompensation cardiorespiratoire au cours d'une polyarthrite rhumatoïde. La Revue de Médecine Interne 30: 994-995.

13. Martinez FJ, Karlinsky JB, Gale ME, Jung-Legg Y, Benditt JO (1990) Intrathoracic lymphadenopathy. A rare manifestation of rheumatoid pulmonary disease. Chest 97 : 1010-1012. [Crossref]

14. Remy-Jardin M, Remy J, Cortet B, Mauri F, Delcambre B (1994) Lung changes in rheumatoid arthritis: CT findings. Radiology 193: 375-382. [Crossref]

15. Despaux J, Manzoni P, Toussirot E, Auge B, Cedoz JP, et al. (1998) Prospective study of the prevalence of bronchiectasis in rheumatoid arthritis using high-resolution computed tomography. Rev Rhum Engl Ed 65: 453-461. [Crossref]

16. Khammassi N, Bayouth A, Abdelhedi H, Balhouane I, Hergli I, Cherif O. [Intrathoracic lymphadenopathy: an unusual manifestation of rheumatoid arthritis]. Rev Pneumol Clin 68: 54-57. [Crossref]

17. Cronstein BN (2007) Interleukin-6--a key mediator of systemic and local symptoms in rheumatoid arthritis. Bull NYU Hosp Jt Dis 65 Suppl 1: S11-15. [Crossref]
18. Tiger LH, Gordon MH, Ehrlich GE, Shapiro B (1976) Liver enlargement demonstrated by scintigraphy in rheumatoid arthritis. J Rheumatol 3: 15-20. [Crossref]

19. Ebert EC, Hagspiel KD (2011) Gastrointestinal and hepatic manifestations of rheumatoid arthritis. Dig Dis Sci 56: 295-302. [Crossref]

20. Ruderman EM, Crawford JM, Maier A, Liu JJ, Gravallese EM, et al. (1997) Histologic liver abnormalities in an autopsy series of patients with rheumatoid arthritis. $\mathrm{BrJ}$ Rheumatol 36: 210-213. [Crossref]

21. Rau R, Pfenninger K, Rau AB, Pfenninger RK, Boni A (1975) Proceedings: Liver function tests and liver biopsies in patients with rheumatoid arthritis. Ann Rheum Dis 34: 198-199. [Crossref]

22. Laffón A, Moreno A, Gutierrez-Bucero A, Ossorio C, Sabando P, et al. (1989) Hepatic sinusoidal dilatation in rheumatoid arthritis. J Clin Gastroenterol 11: 653-657. [Crossref]

23. Bowman SJ (2002) Hematological manifestations of rheumatoid arthritis. Scand $J$ Rheumatol 31: 251-259. [Crossref]

24. Ustun C, Kallab A, Loebl D, Jillela A, Majewski B, et al. (2002) Rheumatoid arthritis and immune thrombocytopenia: a report of two cases. Clin Rheumatol 21: 543-544. [Crossref]

Copyright: @2018 Alaya Z . This is an open-access article distributed under the terms of the Creative Commons Attribution License, which permits unrestricted use, distribution, and reproduction in any medium, provided the original author and source are credited. 